\title{
FORMATION OF THE SYNTHESIS ALGORITHMS OF THE COORDINATING CONTROL SYSTEMS BY MEANS OF THE AUTOMATIC GENERATION OF PETRI NETS
}

\author{
Gurskiy A.A. ${ }^{1}$, Goncharenko A.E. ${ }^{2}$, Dubna S.M. ${ }^{3}$ \\ ${ }^{1,2,3}$ Odessa National Academy of Food Technologies, Odessa \\ E-mail: ${ }^{1}$ Gurskiy.kholod.automatic@mail.ru \\ ${ }^{1}$ ORCID: 0000-0001-5158-2125
}

Copyright (C) 2014 by author and the journal “Automation technological and business - processes”. This work is licensed under the Creative Commons Attribution International License (CC BY). http://creativecommons.org/licenses/by/4.0/

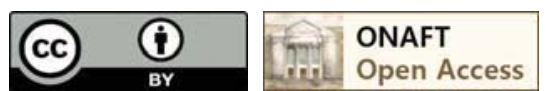

\begin{abstract}
The coordinating control system by drives of the robot-manipulator is presented in this article. The purpose of the scientific work is the development and research of the new algorithms for parametric synthesis of the coordinating control systems. To achieve this aim it is necessary to develop the system generating the required parametric synthesis algorithms and performing the necessary procedures according to the generated algorithm. This scientific work deals with the synthesis of Petri net in the specific case with the automatic generation of Petri nets.
\end{abstract}

Keywords

incidence matrix, Petri net, discrete-continuous net, automatic generation of Petri nets, formation or searching an algorithm, parametric synthesis, coordinating control system, robot manipulator

\section{Introduction}

Coordinating control systems (CCS) is basically a multi-level. Each level of such systems is orientated on the performance of a specific task. It is advisable to carry out parametric synthesis of the coordinating control system according to a specific algorithm. Due to we can obtain the desired quality of system performance.

On the basis of known works [1 - 4] it can be concluded that the parametric synthesis must start from a lower level system and then need to pass to synthesis the upper levels. But in some cases there are other options. For example, it is advisable to start the synthesis of coordinating control system by the drives of the robot manipulator from the top level of the system. It is possible to determine various embodiments of synthesis algorithms coordinating system, and each of these algorithms may lead to different results. In this way, there is the task of formation or searching an algorithm that allows to achieve the desired values of performance indicators of the coordinating control system. Thus, we have the task which similar to the task of reachability of the system in discrete-continuous state space, considering scientific work [5, 6].

In this paper we have developed the module of parametric synthesis in the coordinating control system based on the mathematical apparatus of discrete-continuous network allowing to explore the reachability property of the system through the reduction of continuous and discrete parts of the network [7]. The first development of this system was made in work [8], in which the self-tuning algorithm is presented as Petri net. The proposed system is developed for implement of the parametric synthesis algorithm formation. It is based on the method of reachability test by using the discrete-continuous net. In the research work it is completed development of the machine forming the incidence matrix of Petri net in the discrete-continuous net.

Nowadays the field of use of the Petri nets is greatly expanded. Besides it is developed methods for the synthesis and analysis of Petri nets. This scientific work deals with the synthesis of Petri net in the specific case with the automatic generation of Petri nets [9, 10]. The need of development of Petri nets automatic synthesis is noted in work [11]. The known methods for the synthesis of Petri nets are implemented via their composition [12 - 15]. In our scientific work the synthesis method is related to the rules of the incidence matrix of Petri net forming. 


\section{The purpose of the scientific work}

The purpose of the scientific work is the development and research of the new algorithms for parametric synthesis of the coordinating control systems.

To achieve this aim it is necessary to develop the system generating the required parametric synthesis algorithms and performing the necessary procedures according to the generated algorithm.

Features of the developed system

The coordinating control system by drives of the robot-manipulator is presented as the two-tier system. The block diagram of such system model is presented in figure 1. The model has been implemented by means of MatlablSimulink program. The upper level of the system is associated with the processing of the control errors, and the lower level is associated with the processing of deviation from ratios representing the trajectory of movement of the gripper. The system control law can be represented as follows:

$$
\bar{u}=\bar{u}_{q}+\bar{u}_{p}=\left[\begin{array}{ll}
u_{1 L_{m}} & u_{2 \alpha_{m}}
\end{array}\right]^{T}
$$

where:

$$
\begin{aligned}
& \bar{u}_{q}=\left[\begin{array}{l}
u_{q 1} \\
u_{q 2}
\end{array}\right]=\left[\begin{array}{l}
k_{2} \cdot\left(1+k_{21} \cdot p\right) \\
k_{3} \cdot\left(1+k_{31} \cdot p\right)
\end{array}\right] \cdot \psi(t) \text { is law of lower level control; } \\
& \bar{u}_{p}=\left[\begin{array}{l}
u_{p 1} \\
u_{p 2}
\end{array}\right]=\left[\begin{array}{c}
\left(L_{m z}(t)-L_{m}(t)\right) \cdot k_{1} \cdot\left(1+k_{11} \cdot p\right) \\
\left(\alpha_{m \cdot z}(t)-\alpha_{m}(t)\right) \cdot k_{4}\left(1+k_{41} \cdot p\right)
\end{array}\right] \text { is law of upper level control; }
\end{aligned}
$$

$\psi(t)=f\left(L_{m}\right) \cdot L_{m}(t)+k \cdot \alpha_{m}(t)-b$ is deviation from ratio of the parameters at time $t ; L_{m}(t), \alpha_{m}(t)$ is controlled parameters; $L_{m}$ is position of the gripper arm; $\alpha_{m}$ is the angle of the manipulator arm rotation; $f\left(L_{m}\right)$ is nonlinear dependence describing the path of the gripper movement in coordinates $L_{m}-\alpha_{m}$. Nonlinear dependence represented in the system as a unit $N U$ (figure 2); $k_{1}, k_{11}, k_{2}, k_{21} k_{3}, k_{31}, k_{4}, k_{41}$ is system settings which being defined considering the effect of the separation of the movement; $\alpha_{m . Z}(t), L_{m . Z}(t)$ is setpoints; $p$ is differential operator;

It has been implemented block forming the integral indicators of the system works for the synthesis of coordinating control systems:

$$
\begin{gathered}
J_{1}=\int_{t_{0}}^{t_{1}}\left(\left|\Delta L_{m}(t)\right|+\beta_{1} \cdot\left|\frac{d \Delta L_{m}(t) \mid}{d t}\right|\right) d t=\int_{t_{0}}^{t_{1}}\left(f_{L_{m}}(t)\right) d t ; \\
J_{01}=\left[\int_{t_{0}}^{t_{1}} f_{L_{m}}(t) d t-\int_{t_{2}}^{t_{3}} f_{L_{m}}(t) d t\right]-\left[\int_{t_{1}}^{t_{4}} f_{L_{m}}(t) d t-\int_{t_{2}}^{t_{3}} f_{L_{m}}(t) d t\right] ; \\
J_{2}=\int_{t_{0}}^{t_{1}}\left(\left|\Delta \alpha_{m}(t)\right|+\beta_{2} \cdot \mid \frac{d \Delta \alpha_{m}(t) \mid}{d t}\right) d t=\int_{t_{0}}^{t_{1}}\left(f_{\alpha_{m}}(t)\right) d t ; \\
J_{02}=\left[\int_{t_{0}}^{t_{1}} f_{\alpha_{m}}(t) d t-\int_{t_{2}}^{t_{3}} f_{\alpha_{m}}(t) d t\right]-\left[\int_{t_{1}}^{t_{4}} f_{\alpha_{m}}(t) d t-\int_{t_{2}}^{t_{3}} f_{\alpha_{m}}(t) d t\right] \\
J_{3}=\int_{t_{0}}^{t_{1}} \psi^{2}(t) d t ; \\
J_{03}=\left[\int_{t_{0}}^{t_{1}} \psi^{2}(t) d t-\int_{t_{2}}^{t_{3}} \psi^{2}(t) d t\right]-\left[\int_{t_{1}}^{t_{4}} \psi^{2}(t) d t-\int_{t_{2}}^{t_{3}} \psi^{2}(t) d t\right]
\end{gathered}
$$

where: $\left(t_{1}-t_{0}\right)=\left(t_{3}-t_{2}\right)=\left(t_{4}-t_{1}\right)=\left(t_{5}-t_{3}\right), \quad t_{0}<t_{2}<t_{1}<t_{3}<t_{4}<t ; \quad \Delta L_{m}(t)=L_{m z}(t)-L_{m}(t) ; \quad \Delta \alpha_{m}(t)=\alpha_{m . z}(t)-\alpha_{m}(t) ; \quad \beta_{1}, \beta_{2}$ is coefficients.

On the basis of indicators $J_{01}, J_{02}, J_{03}$ is estimated correctness of the direction for change of CCS settings [8].

The search of parameters $k_{1}, k_{2}, k_{3}, k_{4}$ is performed according to the certain algorithm. Formation of the algorithm in the system is carried out with the aid of the forming machine (FM). Forming machine consists of the machine forming the incidence matrix (MFIM) and the signals determination unit (SDU). SDU implement the necessary synthesis algorithm and 
MFIM generates the matrix of incidence Petri net. Petri net is the synthesis algorithm in the system and the marking of Petri net determines the change of various settings in the blocks of adjusting settings (BAS).

If we consider the coordinating control system together with the circuit of parameter optimization, based on search of algorithm, in that case this system behaves as a logical-dynamic. There is a multimode type of the functioning in the system. For example, the upper-level adjustment mode or the lower level adjustment mode.

The acceptable mathematical tool for the synthesis and study of logic-dynamic systems was implemented on the basis of the discrete-continuous net (DC-net) medium. This medium allows us to explore the attainability of the system using the network reduction rules. The rules network reductions and the methods for checks of reachability are taken into account in the development of the forming machine.

The system model was developed based on the mathematical apparatus of discrete-continuous net in this paper. DC-net can be divided into two parts such as continuously-event part (CEP), and discrete-event part (DEP). The coordinating control system is represent the continuously-event part. Algorithm of parametric synthesis is represent the discrete-event part.

The discrete-event part of the DC-net is described by the equation:

$$
X_{L}^{d}\left(t_{k}\right)=X_{L}^{d}\left(t_{k-1}\right)+|W| \cdot v_{L}^{d}\left(t_{k}\right)+u_{L}^{d}\left(t_{k}\right)
$$

where: $|W|$ is the incidence matrix of the discrete-event part; $v_{L}^{d}\left(t_{k}\right)$ is the control vector which is formed depending on the trigger conditions of transitions Petri net; $u_{L}^{d}\left(t_{k}\right)$ is the input action; $X_{L}^{d}\left(t_{k}\right), X_{L}^{d}\left(t_{k-1}\right)$ is discrete states DEP in times $t_{k}, t_{k-1}$; $X_{L}^{d}\left(t_{k}\right)=\left[\mu\left(p_{1}^{2}\right), \mu\left(p_{2}^{2}\right), \ldots \mu\left(p_{8}^{2}\right)\right]^{T}$; If the position $p_{I}$ is marked $-\mu\left(p_{1}\right)=1$ then $\kappa_{l}$ parameter should be increased i.e., $\mu\left(p_{1}\right)=1 \Rightarrow \uparrow k_{1}$ in this way $\mu\left(p_{2}\right)=1 \Rightarrow \downarrow k_{1}, \mu\left(p_{3}\right)=1 \Rightarrow \uparrow k_{2}, \mu\left(p_{4}\right)=1 \Rightarrow \downarrow k_{2}, \mu\left(p_{5}\right)=1 \Rightarrow \uparrow k_{3}, \mu\left(p_{6}\right)=1 \Rightarrow \downarrow k_{3}$, $\mu\left(p_{7}\right)=1 \Rightarrow \uparrow k_{4}, \mu\left(p_{8}\right)=1 \Rightarrow \downarrow k_{4}$.

Forming of algorithms by means of automatic generation of Petri nets

Checking of the reachability by means the reduction of continuous and discrete parts network consists in convolution the network according to the definite rules to macro-transition. The same way, the discrete Petri net can also expand and generate for forming of algorithm.

It was determined such rules forming incidence matrix for automatic generation of Petri net:

- The row of incidence matrix must begin with 0 or +1 and the values in the rows must alternate $0,1,0-1,0$ and so on.

- $\quad$ The emergence at least one of the number +1 in the column should be accompanied by the emergence at least one of the number -1 in the same column.

- The row can not have two or more consecutive +1 or -1 , even through the zeros.

- In the same row can not be more than two pairs of $+1,-1$ to exclude the creation of complex algorithms.

The fragment of Stateflow chart is shown in figure 2. The Stateflow chart the incidence matrix generation algorithm represents. This Stateflow chart is designed according to the rules of forming incidence matrix. It is shown in figure 2 that the machine is represented by parallel states $C 4, C 5, C 6 \ldots C N$, where $N$ is number of rows of formed the incidence matrix. For emergence -1 this performed the transition from state 19 or state 24 to state 20 or state 25 , and also appears of +1 at the transition from one state 22 or state 26 to state 23 or state 27.

Herewith the transition from the state 19 or state 24 to state 20 or state 25 may be accompanied, depending on the condition data01>-10 for time delay or without this conditions.

It this case the transitions have the such trigger conditions:

$$
\begin{gathered}
\forall p_{i} \in I\left(t_{j}\right): \mu\left(p_{i}\right)=1 \& J_{0 j}<g \& t<t_{k} \\
\forall p_{i} \in I\left(t_{j}\right): \mu\left(p_{i}\right)=1 \& t<t_{k}
\end{gathered}
$$

where: $\mu\left(p_{i}\right)$ is marking input positions for the transition $t_{j} ; g$ is the limit values $J_{0 j}, j=1,2,3 ; t_{k}$ is time delay.

Transitions with different trigger conditions are selected depending on the form of the signals $V s$ data 14 or data 15 , and so on. The signals determine the change in states of machine forming incidence matrix. The emergence of any +1 is implemented depending on the signals values that form the algorithm $(V s)$.

For example, the transition from state 22 to state 23 is carried out according to the conditions of [data24>0.5\&data15>2.5], where data24 is local variable of Stateflow charts, and data15 is signal value that form the algorithm $(V s)$.

Thus, this Stateflow chart is able to provide a great number of various algorithms, maybe even unforeseen by expert. These $V s$ signals may be corrected, if the algorithm is unsatisfactory. 


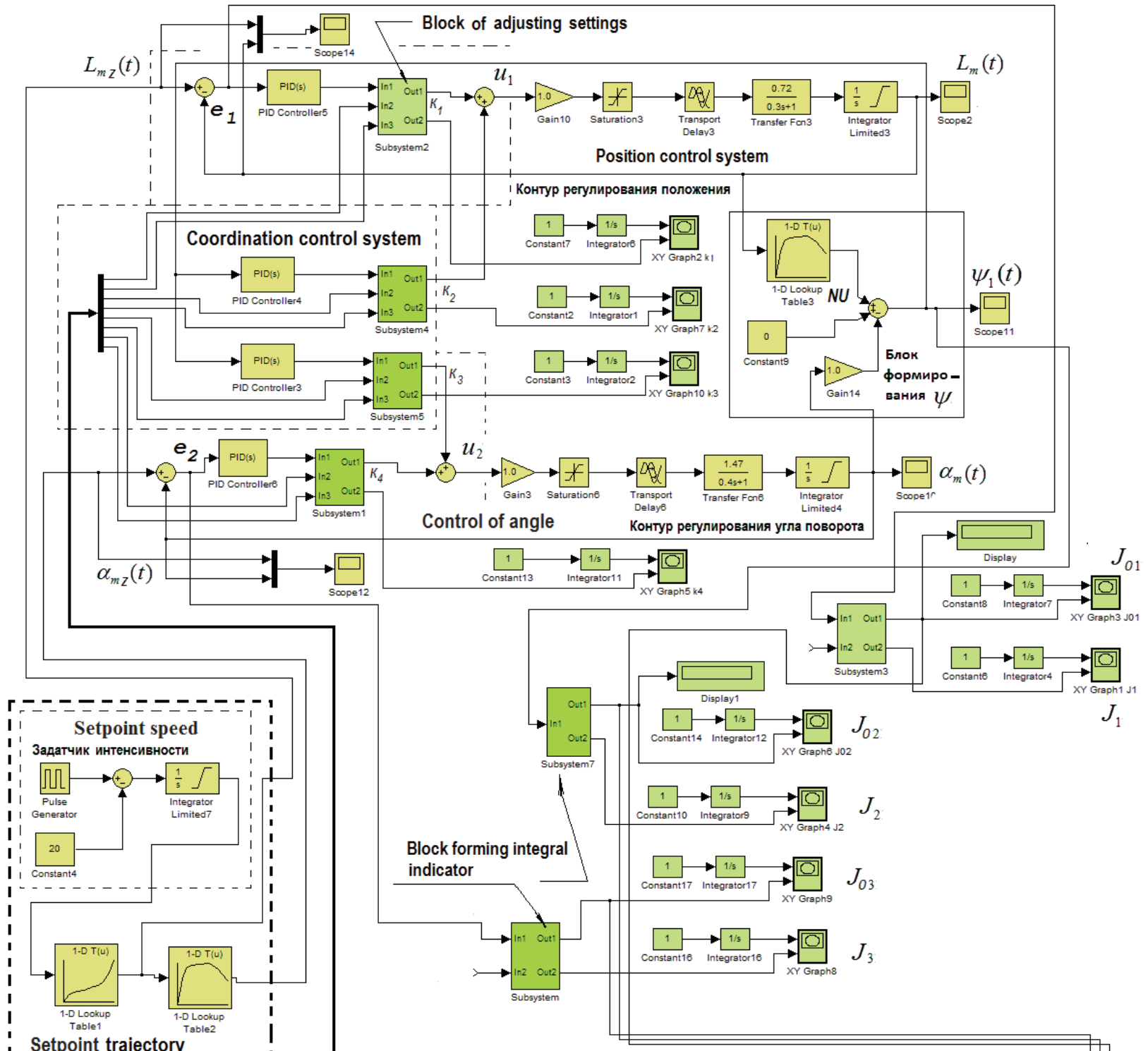

Setpoint trajectory

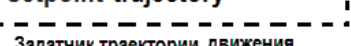

адатчик траектории движения

Circuit of parametric optimization

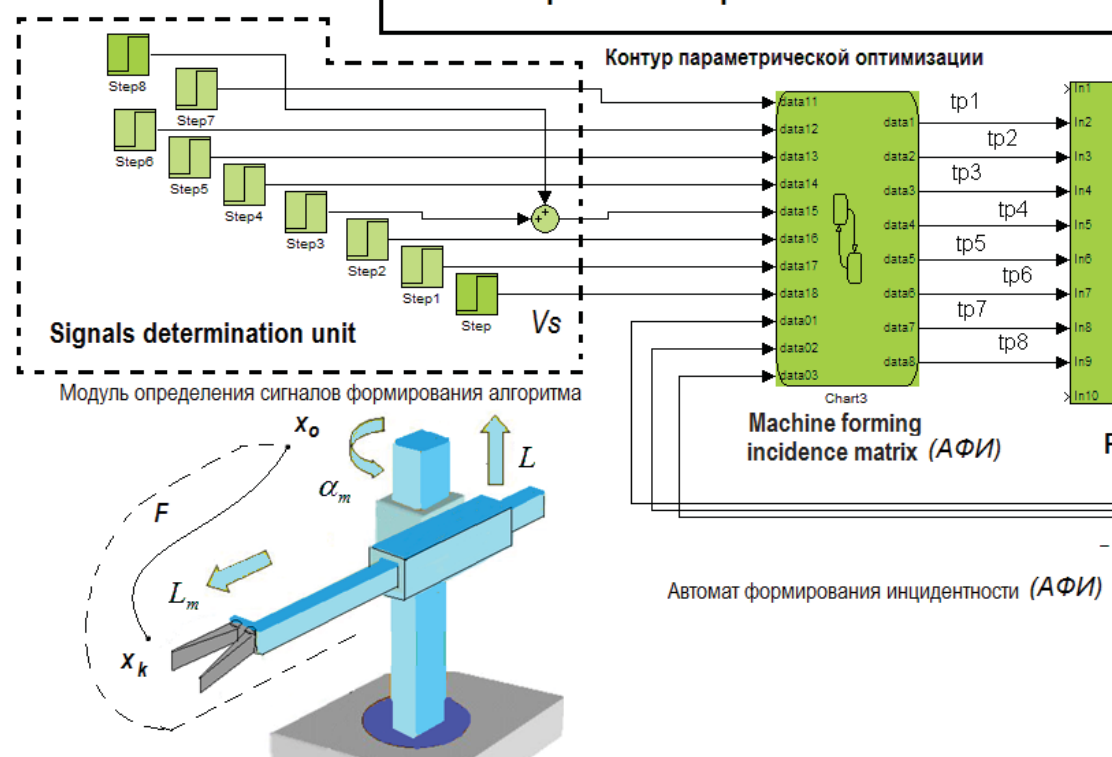

Fig. 1 - The model of the coordinating control system with the circuit of parametric optimization 

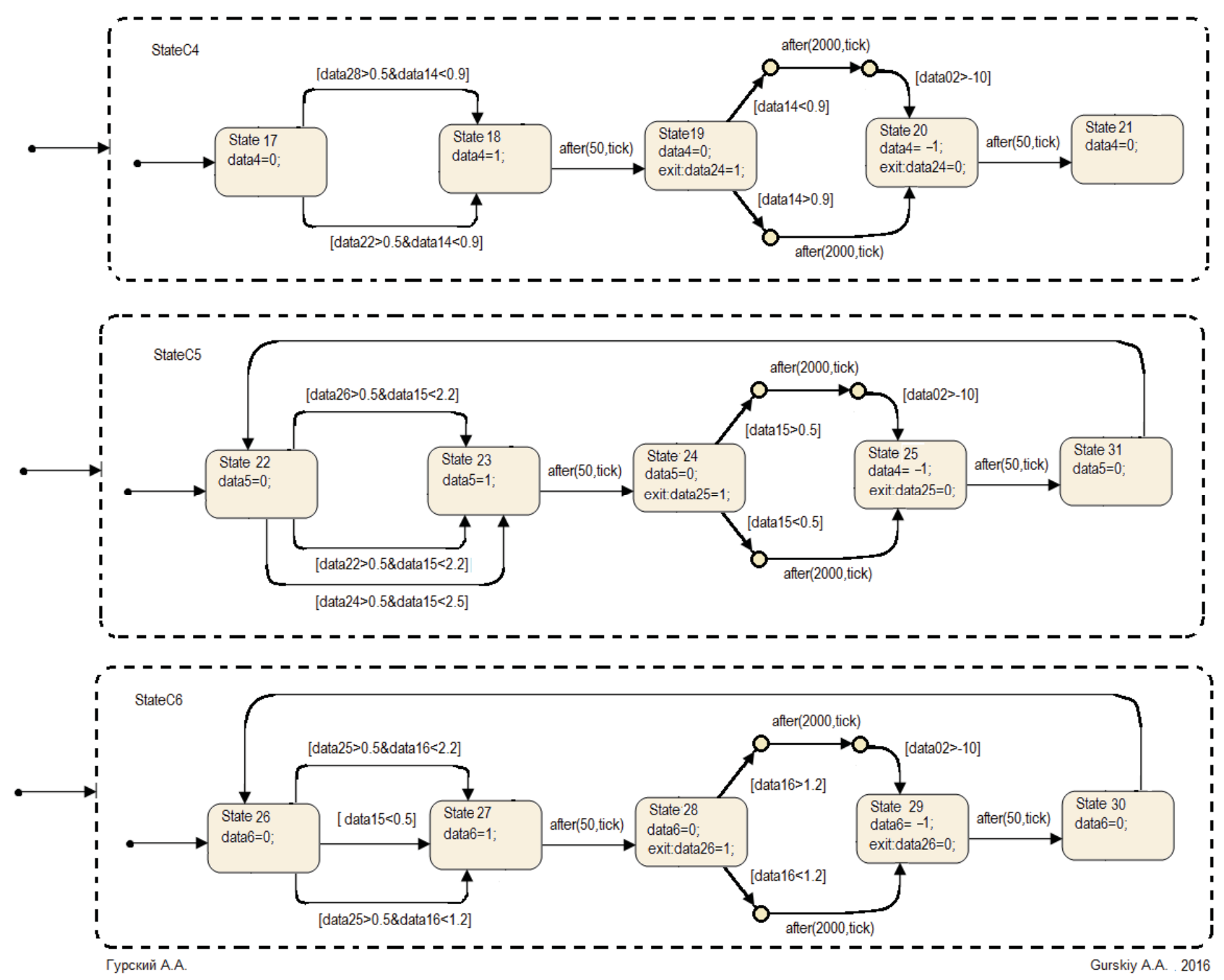

Fig. 2 - Stateflow chart of MATLABISimulink represents the automatic formation of incidence matrix

Analysis of the synthesis processes of coordination control system

Depending on the set signals $V s$ and the indicators values $J_{01}, J_{02}, J_{03}$ the machine MFIM worked out sequence of values. This sequence of values makes of Petri nets matrix incidence. It is presented during the period of parametric synthesis in figure 3. On the basis of the process shown in figure 3, you can make up the incidence matrix. On the basis of the incidence matrix can be composed Petri net, reflecting algorithm for parametric synthesis of the coordinating control system.

Generated incidence matrix of Petri nets has 8 rows according to the number of MFIM outputs and 10 columns according to the number of steps in the Petri net formation. In this case, the incidence matrix is as follows:

$$
\begin{aligned}
& \begin{array}{llllllllll}
t_{1} & t_{2} & t_{3} & t_{4} & t_{5} & t_{6} & t_{7} & t_{8} & t_{9} & t_{10}
\end{array} \\
& \begin{array}{lllllllllll}
t p_{1} & +1 & -1 & 0 & 0 & 0 & 0 & 0 & 0 & 0 & 0
\end{array} \\
& \begin{array}{lllllllllll}
t p_{2} & 0 & +1 & -1 & 0 & 0 & 0 & 0 & 0 & 0 & 0
\end{array} \\
& \begin{array}{lllllllllll}
t p_{3} & 0 & 0 & 0 & +1 & -1 & 0 & 0 & 0 & 0 & 0
\end{array} \\
& \left|A_{L 1}\right|=t p_{4} \quad 0 \quad 00+1 \quad-1 \quad 000000000 \\
& \begin{array}{lllllllllll}
t p_{5} & 0 & 0 & +1 & -1 & 0 & +1 & -1 & 0 & 0 & 0
\end{array} \\
& \begin{array}{lllllllllll}
t p_{6} & 0 & 0 & 0 & +1 & 0 & -1 & +1 & -1 & 0 & 0
\end{array}
\end{aligned}
$$

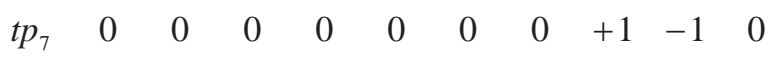

$$
\begin{aligned}
& \begin{array}{lllllllllll}
t p_{8} & 0 & 0 & 0 & 0 & 0 & 0 & 0 & 0 & +1 & -1
\end{array}
\end{aligned}
$$




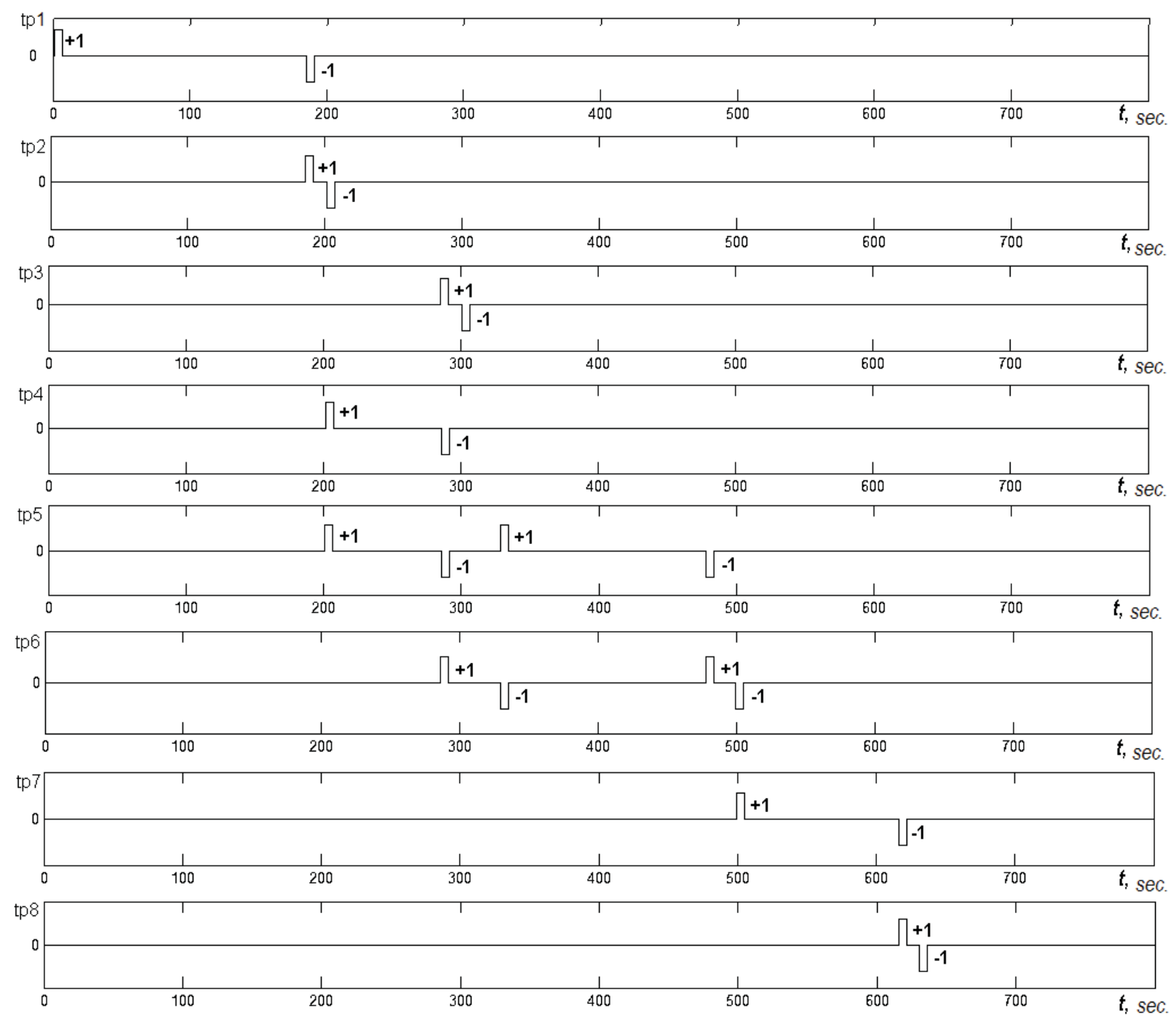

Fig. 3 - The process of Petri nets incidence matrix formation

Thus, with the each step the machine MFIM generates column of the incidence matrix and thereby it develops a Petri net shown in figure 4.

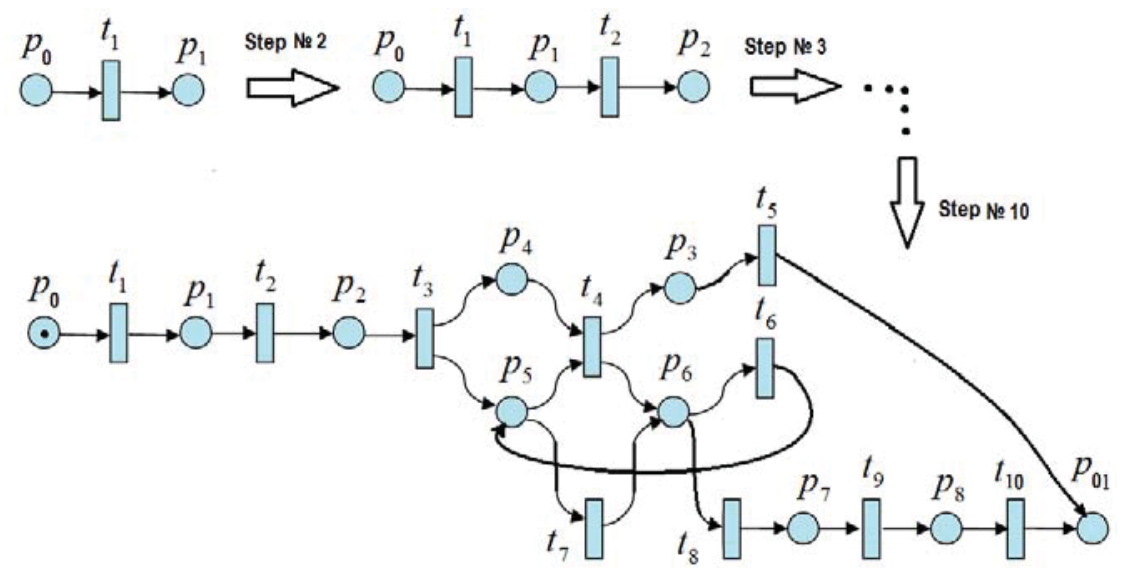

Fig. 4 - The visualization of Petri nets formation representing the parametric synthesis of the coordinating control system algorithm 
The generated Petri net has two conflicting situations. It is shown in figure 4. Thus, it performed trigger of conditions for transitions $t_{4}$ and $t_{7}$ in 200th second parametric synthesis process at the same time. But in 300th second and 500th second the process is performed at the same time of conditions for transitions $t_{6}$ and $t_{8}$. Based on the algorithm of parametric synthesis represented in figure 5 and process of changing marking Petri net shown in figure 6 , we can conclude that the main priority was for the transitions of $t_{4}$ and $t_{6}$.

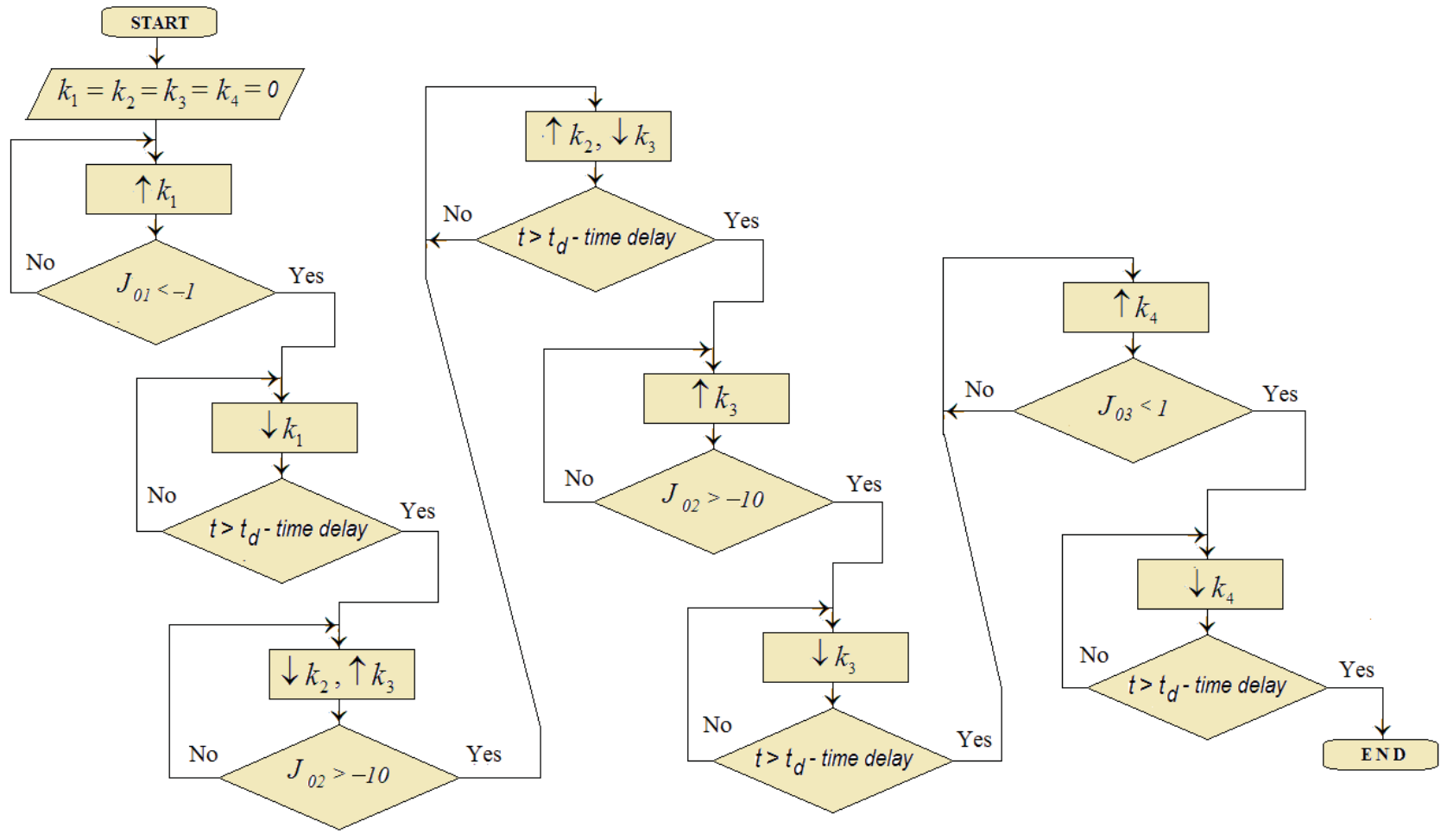

Fig. 5 - The algorithm of parametric synthesis of coordinating control system, $\uparrow k_{i}$ is the increase of parameter $k_{i}$; $\downarrow k_{i}$ is the reduction of parameter $k_{i}$, where $\mathrm{i}=1 \ldots 8$

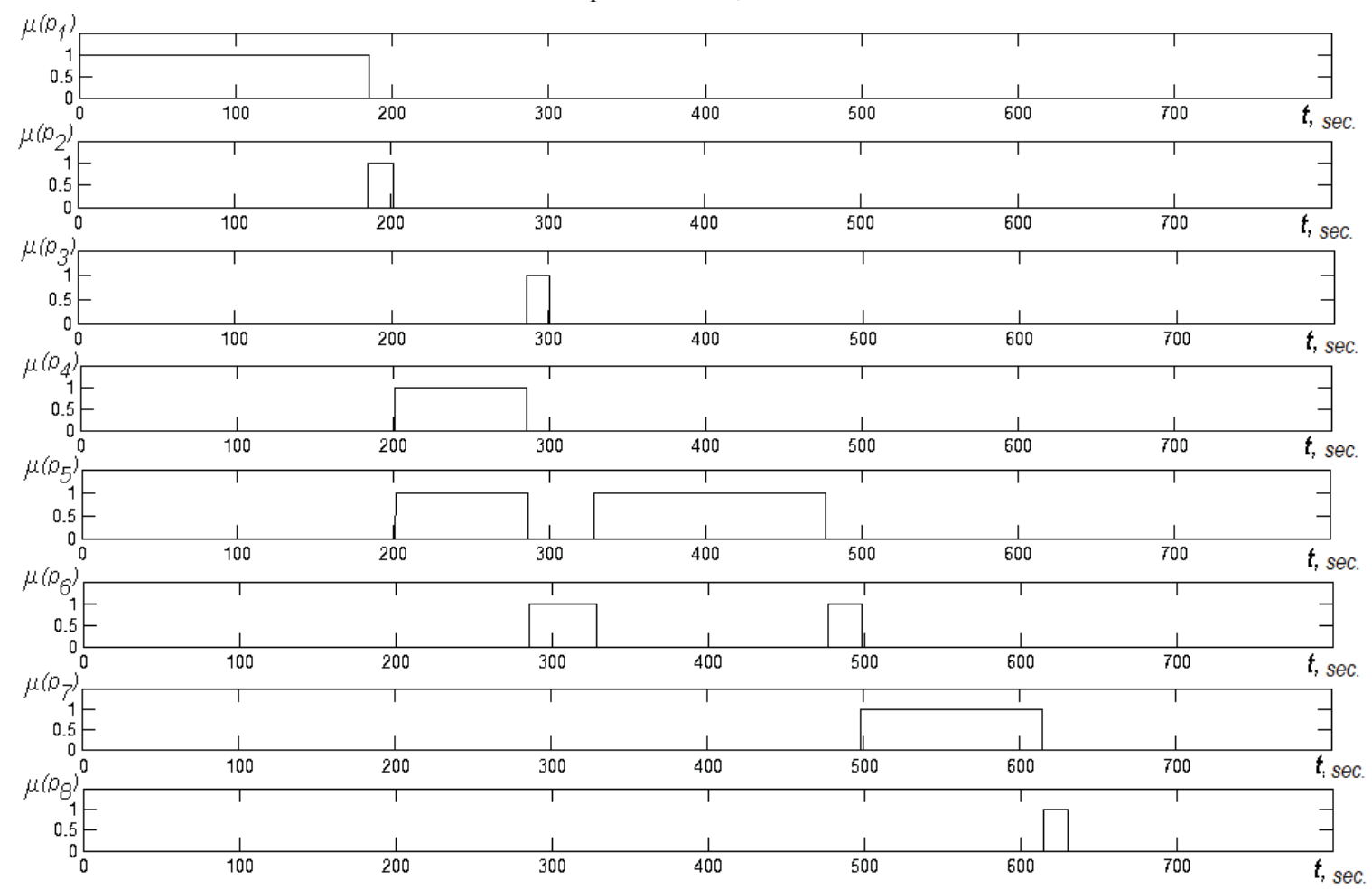

Fig. 6 - The process of changing Petri net marking representing the algorithm of parametric synthesis of coordinating control system 
The definite rules for constructing the incidence matrix are insufficient for the development of machine forming incidence matrix which generates Petri net with non-conflict situations. But in this case, it does not interfere to perform the parametric synthesis of coordinating control system. Thus, the control system parameters change according to the change in marking of Petri net. They are shown in figures 6, 7.

It is shown in figure 8, the $k_{1}$ parameter stops increasing when the value of $J_{01}$ at point A reaches zero. The termination of changing parameters $k_{2}$ and $k_{3}$ occurs at point $B$ and point $C$ is terminated the increase in the parameter $k_{3}$. Finally there is cessation of the $k_{4}$ parameter of increase when $J_{03}$ in the point $D$ reaches zero area.
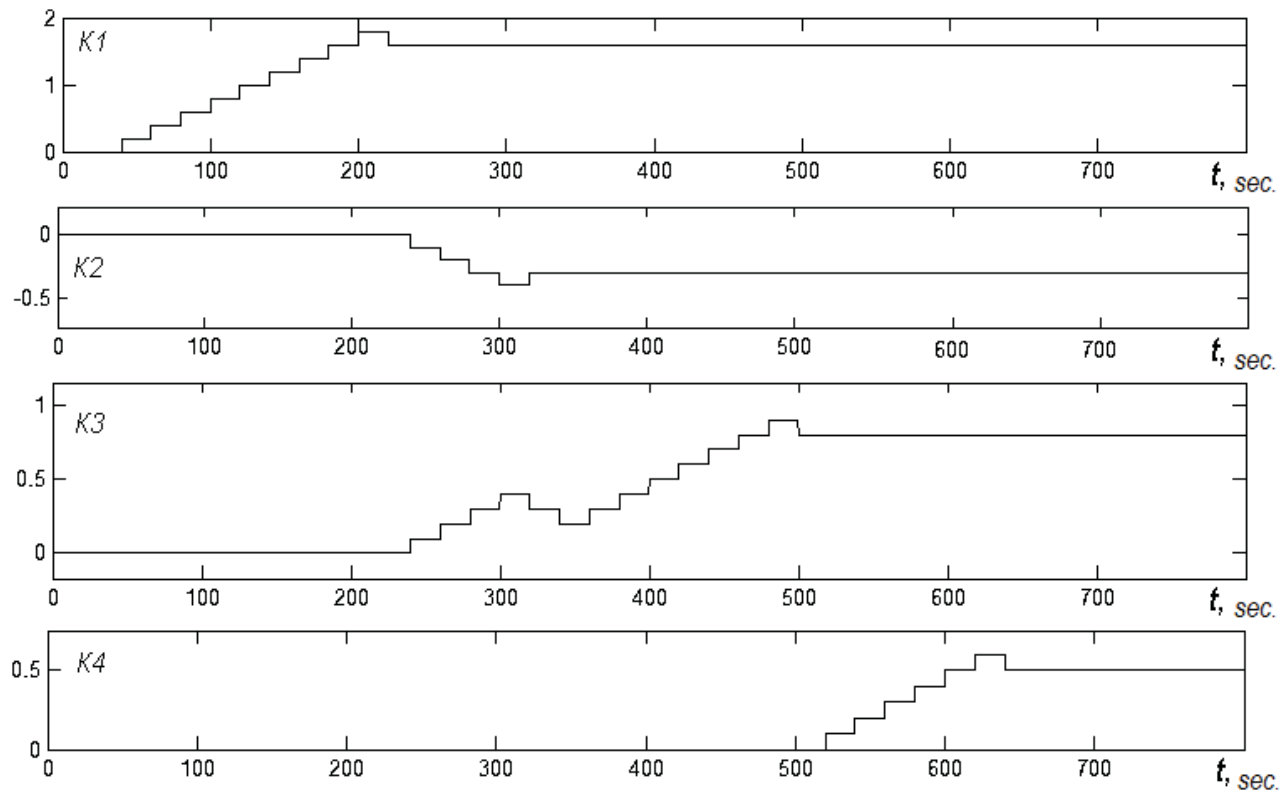

Fig. 7 - Modifying of the settings process in coordinating control system according to the algorithm presented by the generated network Petri
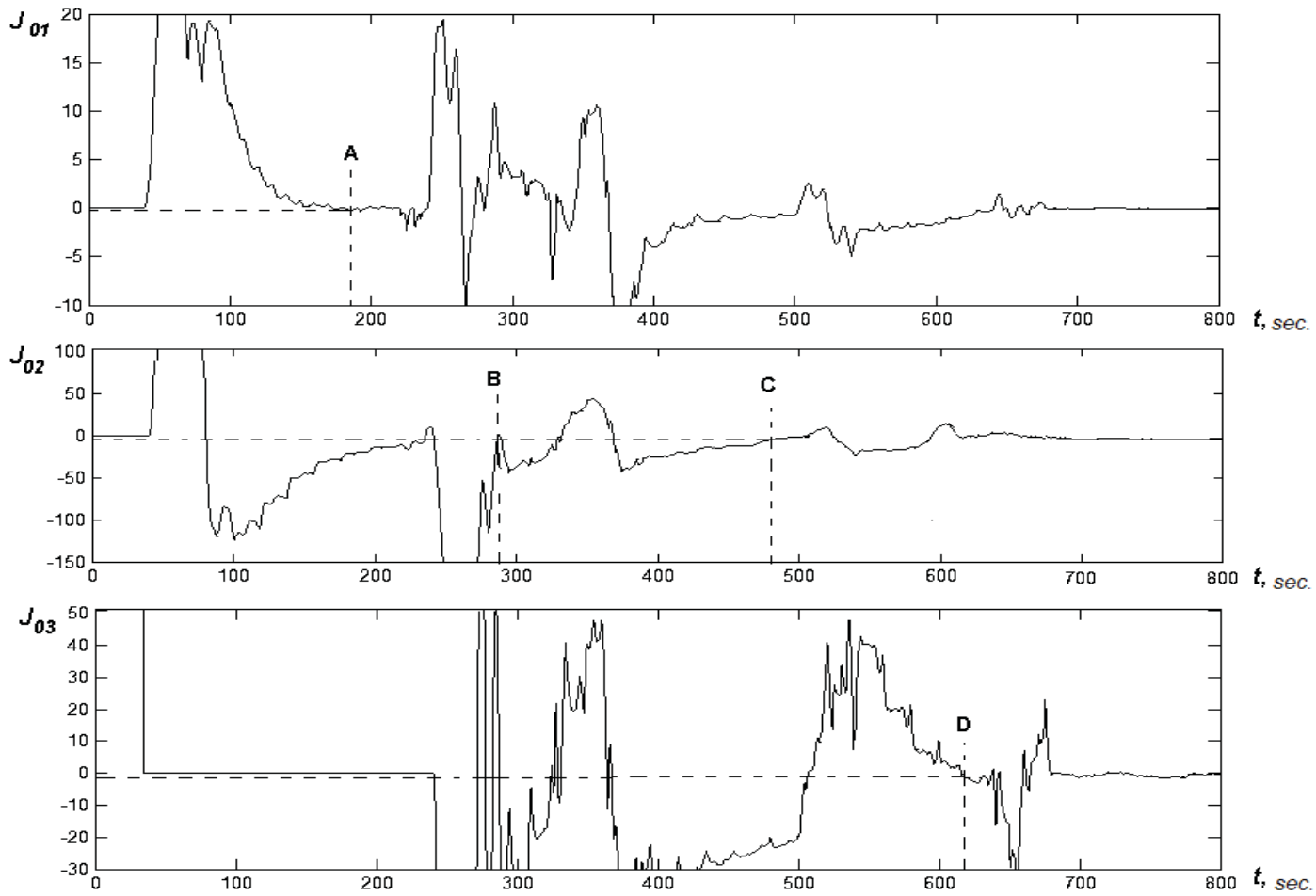

Fig. 8 - The indicators $\left(J_{01}, J_{02}, J_{03}\right)$ changing during the time 
It was changed $V s$ signals to check the forming machine and we got another algorithm. This algorithm has significantly differed from the algorithm shown in figure 5. The incidence matrix was formed (figure 9 and 10) and was formed Petri net shown in figure 11 due to it. This Petri net is represented the algorithm of the parameter optimization of the coordination control systems.

The marking Petri net is changed in conformity with the algorithm of the parametric optimization. The control system parameters $\left(k_{4}, k_{2}, k_{3}\right)$ are adjusted according to the changes of the marking in a Petri net. In this case it has been formed the Petri net which has no conflicts (figure 11).

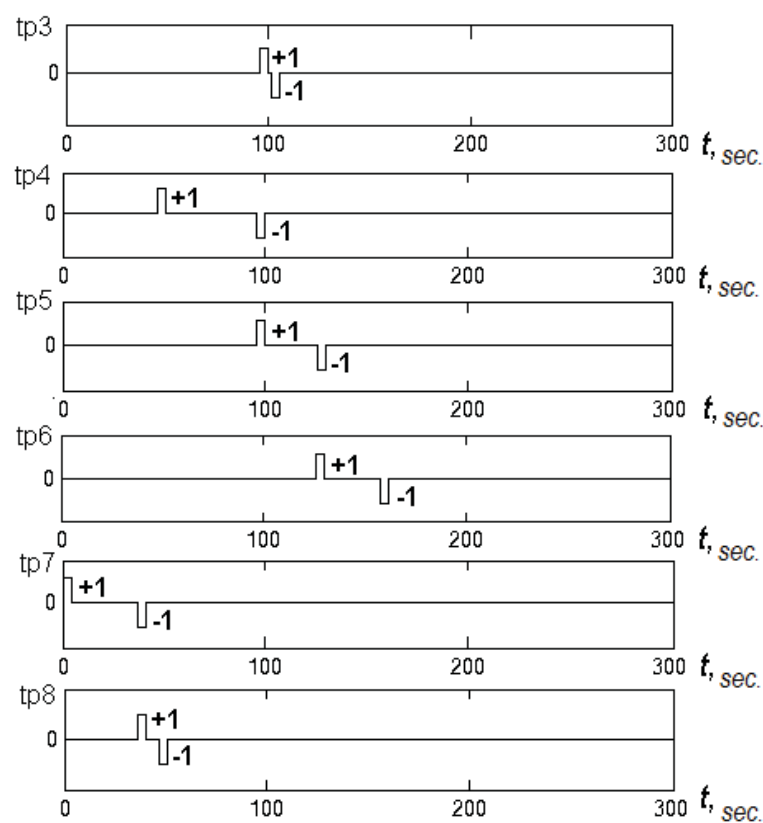

Fig. 9a - The process of the incidence matrix formation

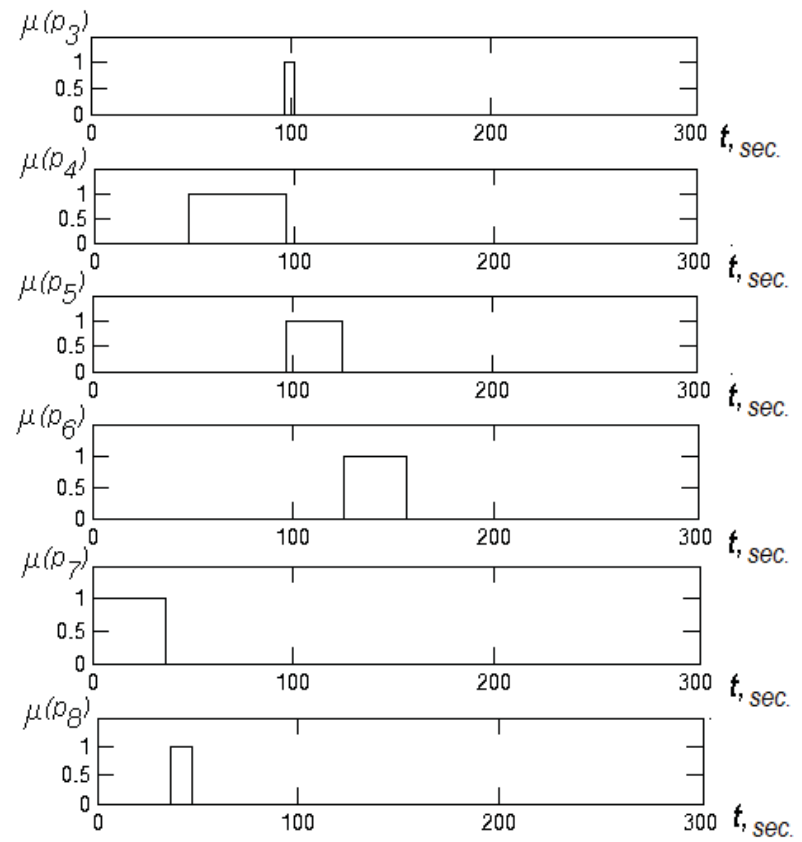

Fig. $9 \mathrm{~b}$ - The process of the Petri net marking change

However, if the signals forming the algorithm $(V s)$ is the random then it is generated Petri net by the random. As a result, it is possible to get a lot of different Petri nets and it is possible to organize the search of the algorithm.

$$
\begin{array}{cccccccc} 
& t_{1} & t_{2} & t_{3} & t_{4} & t_{5} & t_{6} & t_{7} \\
t p_{1} & 0 & 0 & 0 & 0 & 0 & 0 & 0 \\
t p_{2} & 0 & 0 & 0 & 0 & 0 & 0 & 0 \\
t p_{3} & 0 & 0 & 0 & +1 & -1 & 0 & 0 \\
t p_{4} & 0 & 0 & +1 & -1 & 0 & 0 & 0 \\
t p_{5} & 0 & 0 & 0 & +1 & 0 & -1 & 0 \\
t p_{6} & 0 & 0 & 0 & 0 & 0 & +1 & -1 \\
t p_{7} & +1 & -1 & 0 & 0 & 0 & 0 & 0 \\
t p_{8} & 0 & +1 & -1 & 0 & 0 & 0 & 0
\end{array}
$$

a)
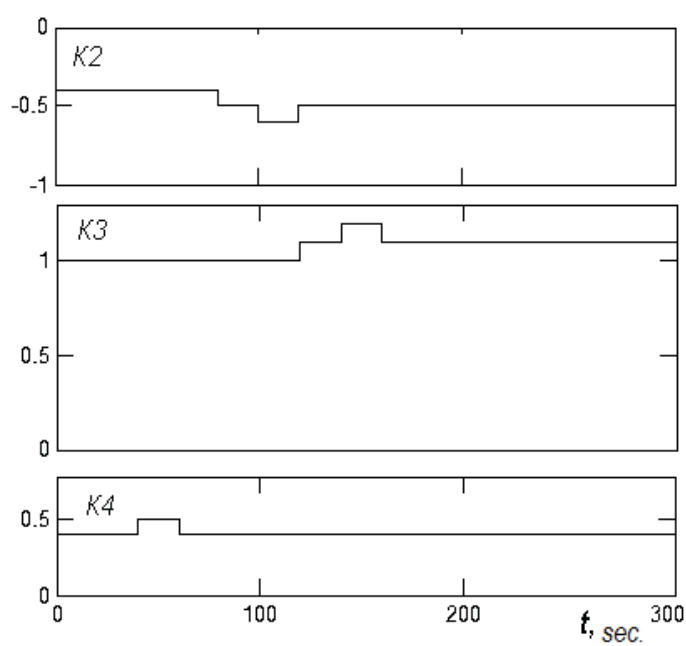

b)

Fig. 10 - The generated incidence matrix of Petri net (Figure 10a.) representing the algorithm of the parameter optimization and the process change of the settings process according to the algorithm (Figure 10b)

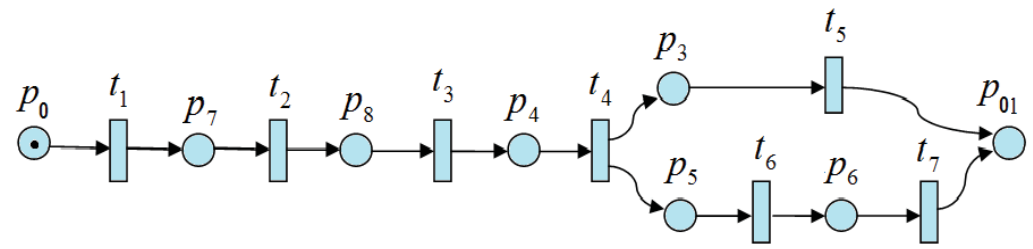

Fig. 11 - The generated Petri net representing the algorithm of the parametric optimization of the control systems 
Comparative analysis of the parametric synthesis results based on the generated algorithms, with the results of the parametric optimization of the coordinating control system by using Response Optimization module of the MATLAB $\backslash$ Simulink environment

To evaluate the formed algorithm of the parametric synthesis of the control system it is necessary to compare the synthesis results with the results of the parametric optimization by using the Response Optimization module of the MATLAB \Simulink environment.

Obviously, using the method of gradient descent the module carry out a number of the additional calculations, missing in the synthesis algorithm that was made by the forming machine.

However, setting the initial values of the parameters $\left(k_{1}=0.3 ; k_{2}=0 ; k_{3}=0 ; k_{4}=0,2\right)$ which give the stable transients but to a considerable extend beyond the established limits, the optimization process produces the desirable results. It can be concluded comparing the results of the parametric optimization shown in figure 12 with the results of parametric synthesis of coordinating control system. The Response Optimization module has implemented the task with the better results (figures 12 , 13).
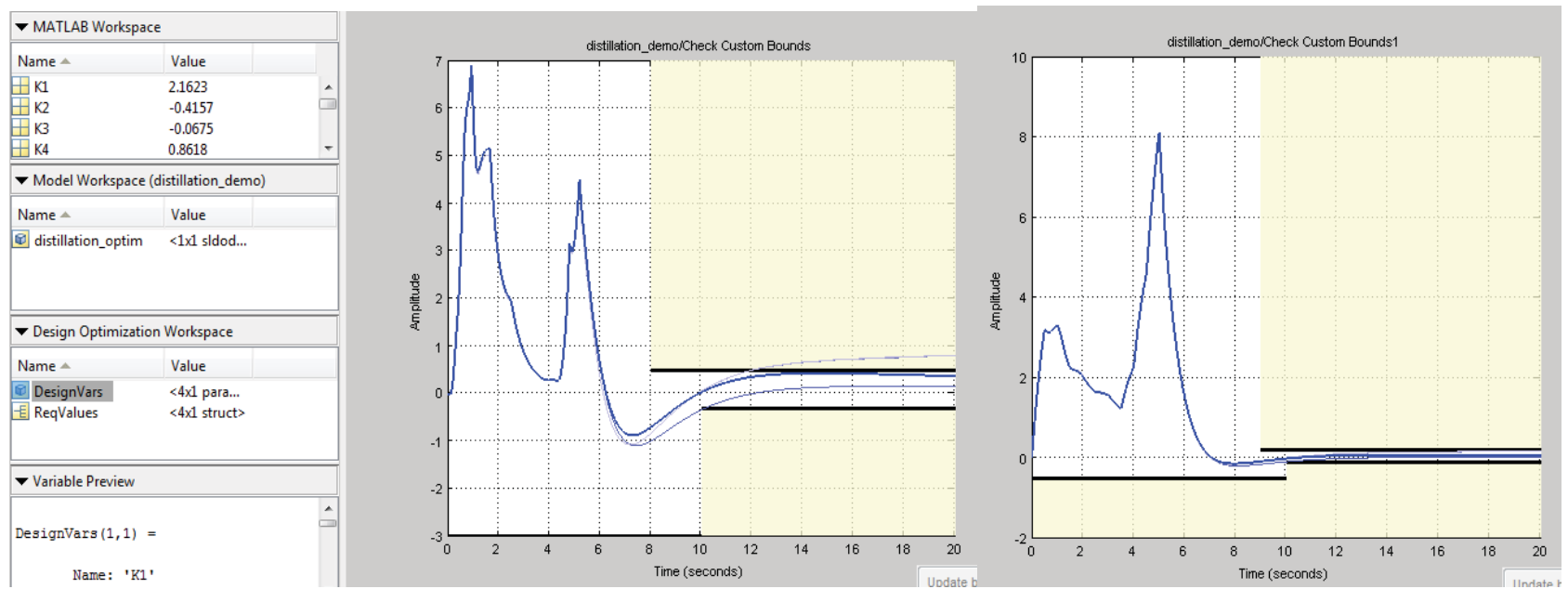

Fig. 12 - The results of the parametric optimization by using the Response Optimization module of the MATLAB $\backslash$ Simulink with the initial the values the $k_{1}=0,3 ; k_{2}=0 ; k_{3}=0 ; k_{4}=0,2$

It we set the initial values of the parameters $\left(k_{1}=k_{2}=k_{3}=k_{4}=0\right)$ that do not provide the stable process, then the results of the optimization are unsatisfactory. It is sown in figure 14. Then the system gives the message «Optimization failed to converge».

It can be concluded that the synthesis algorithm must be deterministic, that under different conditions it is possible to achieve the desired values of efficiency the indicators.

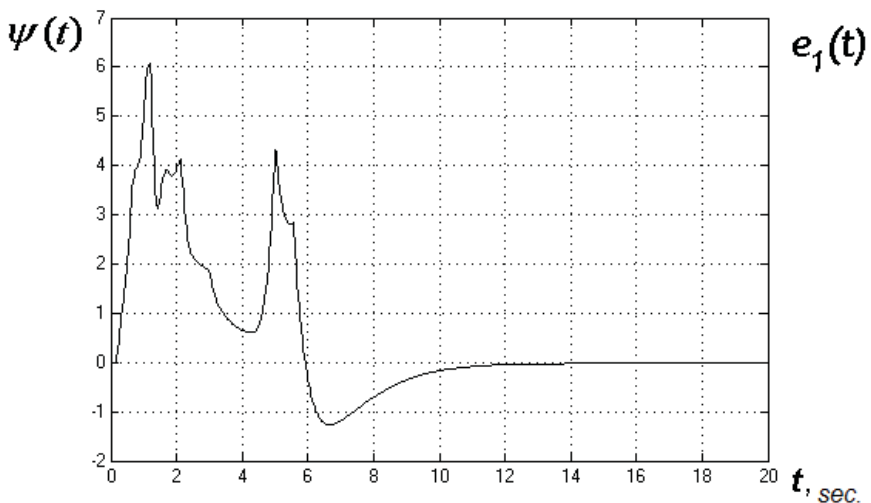

a)

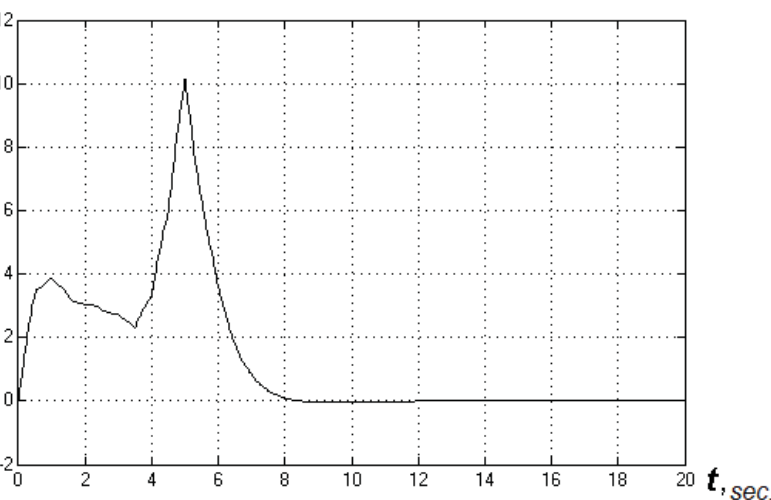

b)

Fig. 13 - Results of parametric synthesis by using the forming machine, the change of the transients in the deviation from the desired trajectory during the time (Figure 14a.) and the error signal in the position control system (Figure 14b) 

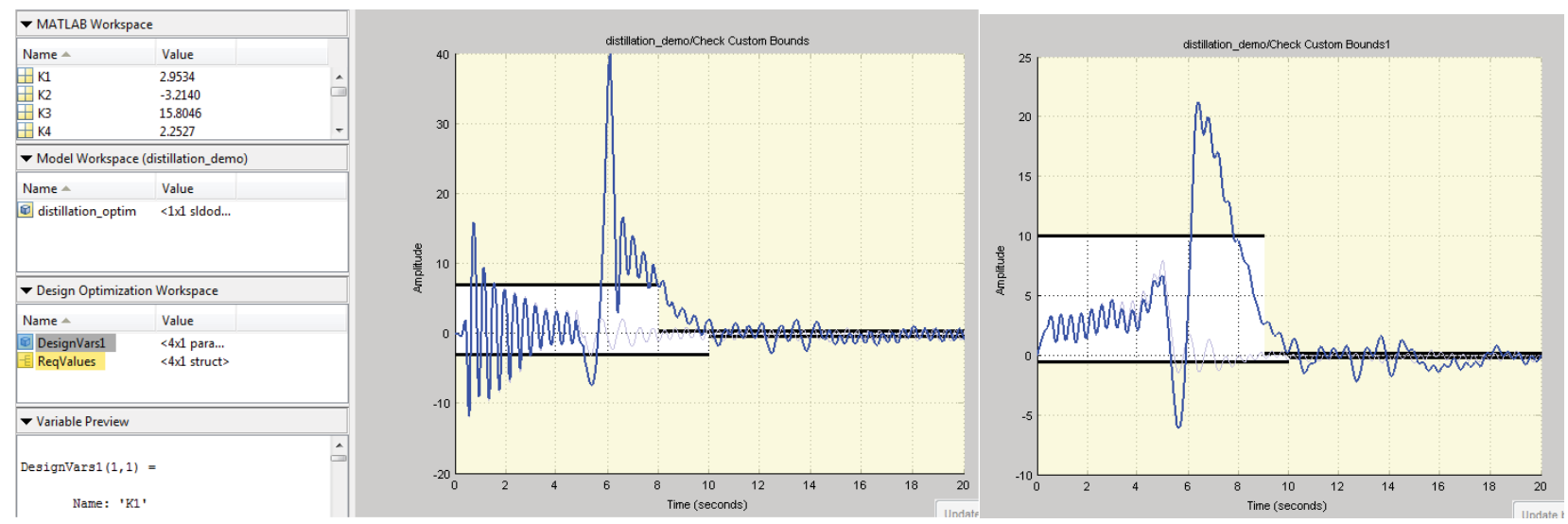

Fig. 14 - Results of the parametric optimization by using the Response optimization module of the MATLAB\Simulink environment with the initial values $k_{1}=k_{2}=k_{3}=k_{4}=0$

\section{Conclusions}

In this paper we developed the synthesis algorithm for, the coordinating control system. This algorithm is implemented on the basis of Petri nets generation. This scientific work will make it possible for us to develop the system forming the synthesis algorithms by means of Petri nets generation.

\section{References}

[1] Bojchuk L.M. Sintez koordinirujushhih sistem avtomaticheskogo upravlenija / L.M. Bojchuk. - M.: «JEnergoatomizdat», 1991. - $160 \mathrm{~s}$.

[2] Miroshnik I.V. Soglasovannoe upravlenie mnogokanal'nymi sistemami / I.V. Miroshnik. - L.: «JEnergoatomizdat», 1990. $-128 \mathrm{~s}$.

[3] Efanov V.N., Muhamedshin E.R. Sintez koordiniruyuschego upravleniya v bortovih informacionno-upravlyayuschih sistemah s ierarhicheskoi strukturoi // Vestnik Ufimskogo gosudarstvennogo aviacionnogo tehnicheskogo universiteta. 2007. - T. 9. - №2. - S. 16-24.

[4] Filimonov A.B., Filimonov N.B. O problematike sinteza koordiniruyuschih sistem avtomaticheskogo upravleniya // Izvestiya Yujnogo federalnogo universiteta. Tehnicheskie nauki. - 2012. - T. 128. - №3. - S. 172-180.

[5] Zgurovskii M.Z., Denisenko V.A. Diskretno neprerivnie sistemi c upravlyaemoi strukturi // K.. : Naukova dumka. 1998. - $350 \mathrm{~s}$.

[6] Denisenko V.A., Nesteryuk A.G. Dostijimost gibridnoi sistemi // Holodilnaya tehnika i tehnologiya. - 2005. - № 3. - S. 87-93

[7] Denisenko V.A., Nesteryuk A.G. Modul proverki dostijimosti diskretno neprerivnih setei // Naukovi praci ONAHT Odesa, 2004. - Vip. 27. - S. 130-137.

[8] Gurskii A.A., Denisenko V.A., Goncharenko A.E. Kontur samonastroiki neiro-nechetkoi sistemi upravleniya holodilnoi ustanovkoi s centrobejnim kompressorom // Avtomatizaciya tehnologichnih i biznes procesiv. - 2014. - № 4. - S. 92101.

[9] Ezpeleta J., Colom J.M. Automatic Synthesis of Colored Petri Nets for the Control of FMS // Robotics and Automation, IEEE Transactions on. - 1997. - Volume 13, Issue 3. - Pages 327-337.

[10] Durmus M.S., Yildirim U., Soylemez M. T. Automatic Generation of Petri Net Supervisors for Railway Interlocking Design // Control Conference (AUCC), 2012 2nd Australian, IEEE, 2012. - Pages 180-185.

[11] Peterson J.L. Petri net theory and the modeling of systems. // Prentice Hall. - 1981. - Chap 6. - S. 153.

[12]Zaicev D.A. Sintez modelei Petri telekommunikacionnih protokolov // Nauchnie trudi Odesskoi nacionalnoi akademii svyazi im. A.S. Popova. - 2005 - №2. - S. 36-42.

[13] He D.W., Strege B., Tolle H., Kusiak A. Decomposition in automatic generation of Petri nets for manufacturing system control and scheduling / DOI: 10.1080/002075400188942 // International Journal of Production Research. - 2000. Volume 38, Issue 6. - Pages 1437-1457.

[14] Kharitonov D.I., Golenkov E.A., Tarasov G.V., Leontyev D.V. A Method of Sample Models of Program Construction in Terms of Petri Nets / (In Russ.) DOI:10.18255/1818-1015-2015-4-563-577 // Modeling and Analysis of Information Systems. - 2015. - Volume 22; Issue 4. - Pages 563-577

[15] Yu D., Liu Z. Towards the Automatic Generation of Petri nets for the OWL-S-based Complex Processes //International Journal of u-and e-Service, Science and Technology. - 2014. - T. 7. - №. 2. - C. 179-188. 